\title{
(2) OPEN ACCESS \\ Nuclear expression of BAP-1 in transvitreal incisional biopsies and subsequent enucleation of eyes with posterior choroidal melanoma
}

\author{
Christina Herrspiegel, ${ }^{1,2}$ Anders Kvanta, ${ }^{1,2}$ Emma Lardner, ${ }^{1}$ Louise Ramsköld Cabaca, ${ }^{1,2}$ \\ Jill Wells, ${ }^{3}$ Katarina Bartuma, ${ }^{1,2}$ Stefan Seregard, ${ }^{1,2}$ Gustav Stålhammar (i) 1,2
}

\begin{abstract}
- Additional material is published online only. To view please visit the journal online (http://dx.doi.org/10.1136/ bjophthalmol-2020-316498).

${ }^{1}$ St. Erik Eye Hospital, Stockholm, Sweden

${ }^{2}$ Department of Clinical Neuroscience, Karolinska Institutet, Stockholm, Sweden ${ }^{3}$ Department of Ophthalmology, Emory University School of Medicine, Atlanta, Georgia, USA
\end{abstract}

Correspondence to Dr Gustav Stålhammar, St. Erik Eye Hospital, 11282 Stockholm, Sweden;

gustav.stalhammar@ki.se

Received 7 April 2020

Revised 13 May 2020

Accepted 14 May 2020

Published Online First

10 June 2020

\section{Check for updates}

(c) Author(s) (or their employer(s)) 2021. Re-use permitted under CC BY-NC. No commercial re-use. See rights and permissions. Published by BMJ.

To cite: Herrspiegel $C$,

Kvanta A, Lardner $\mathrm{E}$, et al.

$\mathrm{Br} J$ Ophthalmol

2021:105:582-586.

\begin{abstract}
Background As a majority of patients with choroidal melanoma do not undergo enucleation, tumour tissue for prognostic testing has to be obtained with alternate methods. Transvitreal incisional biopsies enable histological examination as well as immunohistochemical staining of BRCA1-associated protein-1 (BAP-1).

Methods Fifty-nine patients diagnosed with choroidal melanoma in transvitreal biopsies between years 2003 and 2019 were included. Twenty-one of these patients subsequently underwent enucleation. The level of nuclear expression of BAP-1 in transvitreal biopsies and enucleations was evaluated and the concordance calculated. Metastasis-free survival and HR for metastasis were analysed.
\end{abstract}

Results The mean tumour thickness and diameter at biopsy was $3.8 \mathrm{~mm}$ (SD 2.1) and $9.3 \mathrm{~mm}$ (SD 4.8), respectively. For biopsies, 37 of 59 tumours (63\%) were classified as having high nuclear BAP-1 expression, and $22(37 \%)$ as low. For enucleations, 13 of 21 tumours $(62 \%)$ were classified as having high nuclear BAP-1 expression, and 8 (38\%) as low. Eighty-six per cent of biopsies had an identical BAP-1 classification as the subsequent enucleation, yielding a Cohen's kappa coefficient of 0.70 . Patients with low nuclear BAP-1 expression in transvitreal biopsies had a significantly shorter metastasis-free survival $(p=0.001)$, with a sizeadjusted Cox regression HR for metastasis of $13.0(95 \%$ Cl 3.1 to $54.4, p=0.0004$ )

Conclusion Loss of nuclear BAP-1 expression occurred in a large proportion of the small tumours included in this study. BAP-1 immunoreactivity in transvitreal incisional biopsies of choroidal melanoma is substantially concordant with immunoreactivity in enucleated specimens and identifies patients with poor metastasisfree survival.

\section{INTRODUCTION}

Uveal melanoma (UM) is the most common primary intraocular malignancy in adults. ${ }^{1}$ Less than $5 \%$ of patients have clinically detectable metastases at the time of primary tumour diagnosis. ${ }^{2}$ Within 15 years, however, up to $45 \%$ of patients will have died from metastatic disease even with early enucleation of the eye. ${ }^{3}$ Presumably, this is caused by subclinical dormant micrometastases, most frequently located in the liver. ${ }^{4}$ Once these start growing into clinically detectable lesions, no effective treatment is currently available and the median patient survival is only $4-15$ months. $^{5}$
There are several existing methods for prognostication of UM. Among these, the prognostic utility of detection of loss of expression of the tumour suppressor BRCA1-associated protein-1 (BAP-1) has recently been investigated. ${ }^{67} \mathrm{BAP}-1$ is a nuclear deubiquitinase, implicated in chromatin dynamics, the DNA damage response and regulation of the cell cycle and cell growth. ${ }^{8}$ For the expression and translocation to the nucleus, where BAP-1 can suppress tumour proliferation, one intact allele of the BAP-1 gene is necessary. ${ }^{9}$ In $80 \%$ of metastasizing UM, inactivating mutations in the gene encoding BAP-1, located on chromosome 3p21.1, have been identified. ${ }^{10}$ Further, loss of nuclear BAP-1 protein expression has been observed in tumours without a BAP-1 mutation, suggesting that the proportion of metastasizing UM with loss of nuclear BAP-1 protein expression is even higher. ${ }^{11}$

Even though BAP-1 mutations have been described to occur late in the tumour progression, it remains unclear to what extent nuclear BAP-1 expression is lost in small UM. ${ }^{10}$ Further, whereas BAP-1 immunoreactivity has been well studied on formalin-fixed paraffin embedded tissue sections from enucleated specimens and in transscleral fine needle aspiration biopsies (FNABs), BAP-1 expression in transvitreal biopsies has not been evaluated. ${ }^{69}$ Most patients with UM do not undergo enucleation, and compared with biopsies FNABs do not enable histological examination, do not preserve tissue architecture, retrieve a smaller number of cells and, as shown in other tumours, have less prognostic value. ${ }^{12}{ }^{13}$ Further, BAP-1 status in biopsy material is not necessarily concordant with BAP-1 status in enucleated specimens, considering the difference in tumour volume represented and previous reports of intratumour heterogeneity in BAP-1 expression. ${ }^{14} \mathrm{We}$, therefore, see an opportunity to evaluate the expression of BAP-1 in transvitreal incisional biopsies, its prognostic utility and correlation with the expression in eyes that were subsequently enucleated.

\section{MATERIALS AND METHODS \\ Patients and samples}

All patients with a histopathologically confirmed UM originating in the choroid after a pars plana vitrectomy-assisted incisional (transvitreal) biopsy at the Department of Vitreoretinal Diseases at St. Erik Eye Hospital from 11 March 2003 to 19 March 2019 were included in this study $(n=70)$. 

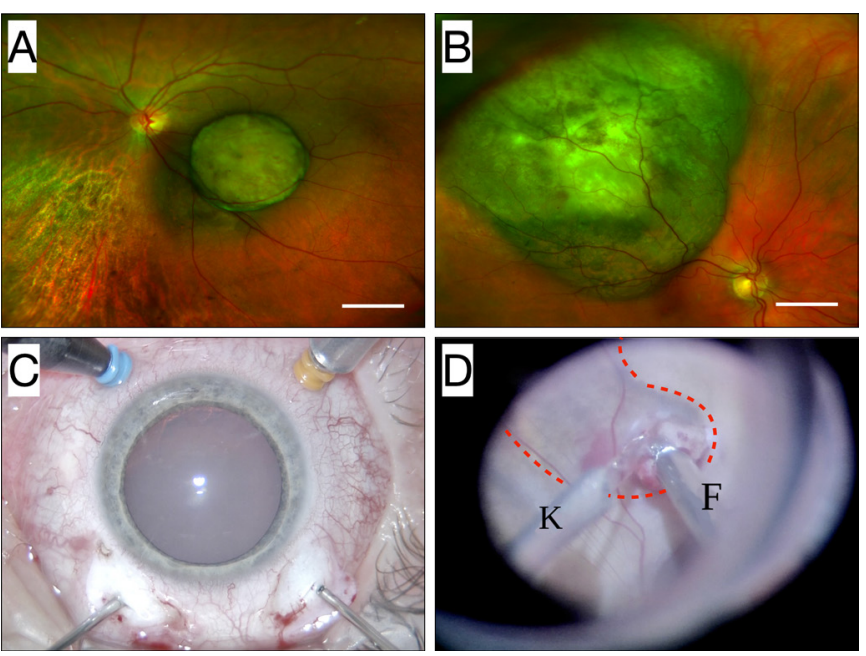

Figure 1 Transvitreal incisional biopsy technique. (A, B) Examples of relatively small dome-shaped subretinal tumours posterior to the equator. In these two cases, choroidal melanoma was suspected but neither slit lamp examinations nor A and B-scan ultrasonographies could establish the diagnosis with sufficient certainty and that is why the patients were offered transvitreal biopsies. (C) A four-port posterior vitrectomy is performed. (D) The slightly pigmented tumour (red dashed line) is observed through the surgical microscope. With a diamond knife (K) a tissue fragment is cut and then removed from the eye with a pair of forceps (F). The procedure is also illustrated in online supplementary video 1 . Scale bars: $2.5 \mathrm{~mm}$.

The procedures were performed for diagnostic purposes. In a majority of cases, tumours can be diagnosed accurately based on posterior segment examination and ultrasonography. These patients do not routinely undergo transvitreal biopsies at our institution. Preoperative informed consent was obtained from all participants. Retrospective clinical data were retrieved from digitalised clinical records. Exclusion criteria were: (1) no follow-up data available $(n=8)$, (2) BAP-1 immunohistochemical staining failed as determined by positive controls $(n=3$, an unstained positive control for either biopsy or enucleation was sufficient for exclusion of the entire case) and (3) prior history of plaque brachytherapy, proton beam irradiation and/or transpupillary thermotherapy $(n=0$, as our previously published experience from BAP-1 staining mainly includes cohorts of untreated tumours). Fifty-nine patients remained in the study.

\section{Transvitreal incisional biopsy technique and specimen handling}

A four-port pars plana vitrectomy was performed. The biopsy site was carefully chosen usually at the location of maximum tumour thickness. A $1 \times 1 \times 1 \mathrm{~mm}$ sample of tumour tissue was incised and removed with forceps. The sample was then immediately put in $4 \%$ buffered formaldehyde and transported to the histopathological laboratory. After fixation for 24 hours, it was embedded in a block of paraffin without centrifugation, sectioning or other manipulation in order to preserve the tissue's histological architecture. This method remained unchanged throughout the period of the study and has previously been described by Seregard et $a l^{15}$ and Kvanta $e t a l^{16}$ in detail and is also presented here as a online supplementary video (figure 1, online supplementary video 1). Enucleated specimens are put in formaldehyde for 24 hours, after which the sclera is opened away from the tumour and the specimen fixated for another 24-72 hours depending on the size of the tumour.

\section{Stains}

To establish the diagnosis of UM versus other subretinal tumours, paraffin-embedded biopsies were cut into multiple $4 \mu \mathrm{m}$ sections and stained with H\&E and a number of immunohistochemical markers, including melanocyte markers Melan-A (Agilent Technologies, Santa Clara, California, USA), HMB45 (Agilent) and S100 (Agilent), proliferation marker Ki67 (Agilent) and epithelial markers CkAE1/3 (Agilent), ER (Novocastra, Leica Biosystems, Wetzlar, Germany), PgR (Novocastra), CdX2 (Abcam, Cambridge, UK) and TTF-1 (Novocastra). The panel of immunostains was applied to all biopsies by default to confirm the morphological impression and to rule out other malignancies. Enucleated specimens were in most cases stained with H\&E and periodic acid-Schiff only, as the UM diagnosis is usually obvious without immunohistochemical confirmation. For this study, an additional $4 \mu \mathrm{m}$ section was cut from both biopsies and enucleations, pretreated in ethylene-diamine-tetraacetic acidbuffer (EDTA) at pH 9.0 for 20 min and incubated with mouse monoclonal antibodies against BAP-1 at dilution 1:40 (clone C-4, Santa Cruz Biotechnology, Dallas, Texas, USA) and a red chromogen, and finally counterstained with haematoxylin and rinsed with deionised water. The deparaffinisation, pretreatment, primary staining, secondary staining and counterstaining steps were run in a Bond III automated stainer for immunohistochemistry/Chromogenic in situ hybridization (IHC/CISH,Leica, Wetzlar, Germany). The dilution had been gradually titrated until optimal staining was achieved, according to manual control by an ophthalmic pathologist.

\section{BAP-1 classification}

The BAP-1 stained tissue sections were screened under low magnification ( $4 \mathrm{x}$ objective). In tumour tissue obtained with transvitreal biopsy, all present tumour cells were selected for grading. In enucleated specimens, 100 cells each in three different three areas exhibiting the most intense BAP-1 staining were selected for grading. Nuclear immunoreactivity was evaluated in high magnification ( $20 \mathrm{x}$ and/or $40 \mathrm{x}$ objective). The level of BAP-1 expression was classified as low if $<33 \%$ of the tumour cell nuclei were positive, and as high if $\geq 33 \%$ were positive (figure 2). This threshold has previously been found to correlate to risk for metastasis and gene expression class. ${ }^{7}$ The first and last author performed the classifications jointly in a masked fashion under a multiheaded microscope, blinded to patient identities and outcomes. Only nuclear staining of BAP-1 was evaluated and henceforth when referring to BAP-1 IHC, we mean the nuclear staining. External controls were used (skin and BAP-1 positive UM tissue obtained from previous enucleations). In enucleated specimens, there are also several internal controls (eg, ganglion layer of retina and/or normal choroidal/iris melanocytes and/or optic nerve nuclei).

\section{Statistical methods}

For measurement of interspecimen concordance, the percentage of identically classified cases in transvitreal biopsies and enucleated specimens and Cohen's kappa statistics $(\kappa)$ were computed. ${ }^{17}$ For correlation with metastatic risk, BAP-1 classifications of transvitreal biopsies were evaluated with Cox proportional hazards analysis adjusted for tumour diameter and thickness, and with Kaplan-Meier metastasis-free survival. To test whether our data met the proportional hazard assumption, we built a Cox regression model with a time-dependent versus a timeindependent variable (BAP-1 classification low/high). Follow-up was defined as the time in months from biopsy to the last patient 


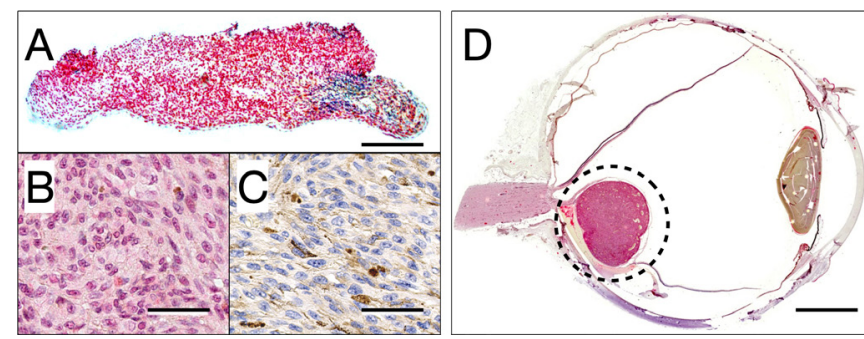

Figure 2 Illustration of BAP-1 immunohistochemistry. (A) A nonpigmented tumour sample removed with the transvitreal incisional biopsy technique and stained with BAP-1. (B) Tumour cells that have a normal expression of the protein turn red in the cell nucleus, whereas (C) cells that have a low expression of the protein stain blue in the nucleus. Loss of nuclear expression represents a clear increased risk of subsequent metastatic development. In this particular case, all tumour nuclei had lost their BAP-1 expression. (D) In an enucleated specimen, the full tumour is visible as a rounded protrusion in the posterior aspect of the eye (circled). This particular eye was enucleated and not irradiated with plaque brachytherapy because of the unfavourable location in close vicinity of the optic nerve. The tumour had high nuclear BAP-1 expression in both biopsy and enucleated specimen. Scale bars: $a$, $0.25 \mathrm{~mm}$. B and C, $50 \mu \mathrm{m}$. D, $5 \mathrm{~mm}$. BAP-1, BRCA1-associated protein-1.

encounter. Differences with a $\mathrm{p}<0.05$ were considered significant, all p values being two sided. All statistical analyses were performed using IBM SPSS statistics V.25.

\section{RESULTS}

\section{Descriptive}

Of the 59 patients included, 27 were female and 32 were male. Twenty-one patients subsequently underwent enucleation. The main reason for enucleation was unfavourable tumour location for brachytherapy (eg, too close to the optic nerve) in 11, tumour size too large for brachytherapy in 4 , extrascleral extension in 2 , extensive retinal detachment in 2 , dense vitreous bleeding in 1 and low potential for meaningful vision in 1 . The mean age at transvitreal biopsy was 61 years (SD 17). Extrascleral extension was seen in $2(3 \%)$ patients. The mean tumour thickness at biopsy was $3.8 \mathrm{~mm}$ (SD 2.1, minimum-maximum 1.0-10.5) and mean tumour diameter $9.3 \mathrm{~mm}$ (SD 4.8, minimum-maximum 2.0-25.0). Fifty-one tumours (86\%) were of T-category 1 or 2, as defined by the American Joint Committee on Cancer (AJCC). No patient had undergone plaque brachytherapy, proton beam irradiation and/or transpupillary thermotherapy prior to biopsy. At enucleation, 11 tumours were of AJCC T-category 1 (52\%), 4 tumours of category 2 (19\%), 3 tumours of category $3(14 \%)$ and 3 tumours of category $4(14 \%)$. The main reason for enucleation was unfavourable tumour location $(n=11)$. The median follow-up after biopsy was 5.3 years (IQR 5.1, minimummaximum 0.4-14.2). Within this time period 17 patients (29\%) developed metastasis and 12 patients (20\%) died from metastatic disease. No recurrences in the orbit or periocular tissues were recorded. Adequate tissue for diagnosis was obtained in 59 patients $(100 \%$, table 1$)$.

\section{Concordance in BAP-1 classification}

For the transvitreal biopsies, 37 of 59 tumours (63\%) were classified as having high nuclear BAP-1 expression, and $22(37 \%)$ as low. For the enucleated specimens, 13 of 21 tumours (62\%) were classified as having high nuclear BAP-1 expression, and $8(38 \%)$ as low. Seventeen biopsies and four enucleations had complete absence of nuclear staining. Of the 22 biopsies that

\begin{tabular}{|c|c|c|}
\hline \multicolumn{2}{|l|}{ Biopsies, n } & 59 \\
\hline \multicolumn{2}{|c|}{ Subsequent enucleations of same eye, $n$} & 21 \\
\hline \multicolumn{3}{|c|}{ Main reasons for enucleation, $\mathrm{n}$} \\
\hline \multicolumn{2}{|c|}{ Unfavourable tumour location } & 11 \\
\hline \multicolumn{2}{|c|}{ Tumour size too large for brachytherapy } & 4 \\
\hline \multicolumn{2}{|c|}{ Extrascleral extension } & 2 \\
\hline \multicolumn{2}{|c|}{ Extensive retinal detachment } & 2 \\
\hline \multicolumn{2}{|c|}{ Dense vitreous bleeding } & 1 \\
\hline \multicolumn{2}{|c|}{ Low potential for meaningful vision } & 1 \\
\hline \multicolumn{2}{|c|}{ Mean age at biopsy, years (SD) } & $61(17)$ \\
\hline \multicolumn{3}{|c|}{ Sex, $n(\%)$} \\
\hline \multicolumn{2}{|l|}{ Female } & $27(46)$ \\
\hline \multicolumn{2}{|l|}{ Male } & $32(54)$ \\
\hline \multicolumn{2}{|c|}{ Median symptom duration before biopsy, years (IQR) } & $0.5(1.9)$ \\
\hline \multicolumn{3}{|c|}{ Presentation, $\mathrm{n}(\%)^{*}$} \\
\hline \multicolumn{2}{|c|}{ Shadow in visual field } & $19(32)$ \\
\hline \multicolumn{2}{|c|}{ Visual impairment } & $5(9)$ \\
\hline \multicolumn{2}{|l|}{ Pain } & $4(7)$ \\
\hline \multicolumn{2}{|l|}{ Floaters } & $3(5)$ \\
\hline \multicolumn{2}{|c|}{ No of incidental* tumour findings (\%) } & $28(48)$ \\
\hline \multicolumn{2}{|c|}{ Mean visual acuity at biopsy } & $20 / 50$ \\
\hline \multicolumn{2}{|c|}{$\begin{array}{l}\text { Mean tumour thickness at biopsy, mm (SD, min- } \\
\max \text { ) }\end{array}$} & $3.8(2.1,1.0-10.5)$ \\
\hline \multicolumn{2}{|c|}{ Mean tumour diameter at biopsy, mm (SD, min-max) } & $9.3(4.8,2.0-25.0)$ \\
\hline AJCC T-category & At biopsy, n (\%)† & At enucleation $\mathrm{n}(\%) \dagger$ \\
\hline 1 & $37(63)$ & $11(52)$ \\
\hline 2 & $14(24)$ & $4(19)$ \\
\hline 3 & $4(7)$ & $3(14)$ \\
\hline 4 & $4(7)$ & $3(14)$ \\
\hline $\begin{array}{l}\text { Median days fror } \\
\text { min-max) }\end{array}$ & enucleation $(\mathrm{IQR}$ & $42(23,13-2512)$ \\
\hline Median follow-u & R, minimum-maximum) & $5.3(5.1,0.4-14.2)$ \\
\hline Metastasis (\%) & & \\
\hline Yes & & $17(29)$ \\
\hline No & & $42(71)$ \\
\hline Melanoma-relate & $(\%)$ & \\
\hline Yes & & $12(20)$ \\
\hline No & & $1(2)$ \\
\hline Alive & & $46(78)$ \\
\hline Biopsy BAP-1 cla & n (\%)‡ & \\
\hline High & & $37(63)$ \\
\hline Low & & $22(37)$ \\
\hline Enucleation BAP & ation, n (\%)‡ & \\
\hline High & & $13(62)$ \\
\hline Low & & $8(38)$ \\
\hline
\end{tabular}

*Incidental tumour findings refers to tumours that were discovered upon fundus examination for other reasons, for example, screening for diabetic retinopathy, an optometrist's examination or during preparations for cataract surgery.

tPercentage does not total 100 due to rounding.

$\$ 17$ of 59 biopsies and 4 of 21 enucleations had complete absence of nuclear staining ( $0 \%$ positive tumour nuclei).

AJCC, American Joint Committee on Cancer; BAP-1, BRCA1-associated protein-1.

were classified as having low nuclear BAP-1 expression, 12 $(55 \%)$ were of AJCC T-category 1,7 (32\%) of T-category 2, $2(9 \%)$ of T-category 3 and 1 (5\%) of T-category 4 (table 2). Identical classification of nuclear BAP-1 expression was obtained in 18 of $21(86 \%)$ patients with transvitreal biopsies and subsequent enucleations (table 3). Two patients had low nuclear BAP-1 expression in their biopsies but high nuclear BAP-1 expression in 
Table 2 Proportion of biopsies and enucleations with low BAP-1 expression across AJCC tumour size categories

\begin{tabular}{lll}
\hline AJCC T-category & $\begin{array}{l}\text { BAP-1 low at biopsy, } \\
\mathbf{n}(\%)\end{array}$ & $\begin{array}{l}\text { BAP-1 low at enucleation, } \\
\mathbf{n}(\%)\end{array}$ \\
\hline 1 & 12 of $37(32)$ & 5 of $11(45)$ \\
2 & 7 of $14(50)$ & 1 of $4(25)$ \\
3 & 2 of $4(50)$ & 1 of $3(33)$ \\
4 & 1 of $4(25)$ & 1 of $3(33)$ \\
\hline
\end{tabular}

AJCC, American Joint Committee on Cancer; BAP-1, BRCA1-associated protein-1.

their enucleated tumours. One patient had high BAP-1 expression in the biopsy but low expression of BAP-1 in the enucleated tumour. The sensitivity and specificity for the classification in subsequent enucleations specimens was $88 \%$ and $85 \%$, respectively, and the positive and negative predictive value $78 \%$ and $92 \%$, respectively. The Cohen's kappa value was 0.70 , indicating substantial agreement.

\section{Survival}

Patients with low nuclear BAP-1 expression in transvitreal biopsies had a significantly increased HR for metastasis. In a multivariate Cox proportional hazards analysis with tumour diameter, tumour thickness and BAP-1 classification as covariates, the independent HR for metastasis was 13.0 (95\% CI 3.1 to 54.4, $\mathrm{p}=0.0004)$ with a BAP-1 expression classified as low, and 1.2 ( $95 \%$ CI 1.1 to $1.3, p=0.005$ ) with each increased millimetre in tumour diameter (figure 3). Tumour thickness was not independently associated with metastasis (HR 1.0 for each increased millimetre in thickness, 95\% CI 0.8 to $1.3, \mathrm{p}=0.96$, table 4). The predictor satisfied the proportional hazard assumption in a Cox regression model with a time-dependent versus a timeindependent treatment $(\mathrm{p}=0.36)$.

In Kaplan-Meier analysis, patients had a significantly shorter metastasis-free survival if their tumours had a low nuclear BAP-1 expression in transvitreal biopsies $(\log$-rank $\mathrm{p}=0.001)$.

\section{DISCUSSION}

In this study, we have shown that nearly $40 \%$ of UM diagnosed with transvitreal biopsies have low BAP-1 expression. Furthermore, the BAP-1 expression in these biopsies correlates with the BAP-1 expression in enucleated specimens and identifies patients with poor metastasis-free survival.

Previous studies have found a loss of BAP- 1 expression in $43 \%$ to $63 \%$ of larger tumours. ${ }^{714} 17$ As our cohort mainly consisted of AJCC T1 tumours, of which 55\% had low BAP-1 expression, one can conclude that in a large proportion of UM, loss of BAP-1 expression occurs when the tumour is still small. This is important for understanding the metastatic process in which tumour cells with different phenotypes interact with the extracellular matrix, fibroblasts and the immune system to gain access to the systemic circulation, and for the prognostic perspective in

\begin{tabular}{lllc}
\hline $\begin{array}{l}\text { Table } 3 \\
\text { biopsies and subsequent enucleations }\end{array}$ & $\begin{array}{l}\text { Classification table of BAP-1 expression in transvitreal } \\
\text { Enucleation, BAP- } \\
\text { 1 low, } \mathbf{n}\end{array}$ & $\begin{array}{l}\text { Enucleation, BAP- } \\
1 \text { high, } \mathbf{n}\end{array}$ & Total \\
\hline & 7 & 2 & 9 \\
\hline Biopsy, BAP-1 low & 1 & 11 & 12 \\
\hline Biopsy, BAP-1 high & 8 & 13 & 21 \\
\hline Total & & & \\
\hline
\end{tabular}

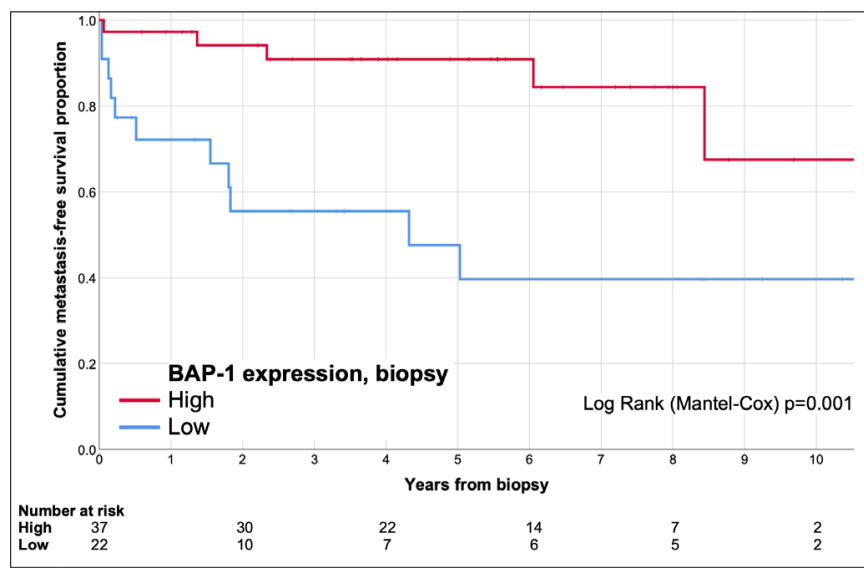

Figure 3 Kaplan-Meier curve. Patients with tumours who had low nuclear BAP-1 expression in transvitreal incisional biopsies (blue) had significantly shorter metastasis-free survival than patients with tumours who had high nuclear BAP-1 expression (red, log-rank $p=0.001$ ). BAP-1, BRCA1-associated protein-1.

which high-risk characteristics of UM are apparently established early on in tumour progression. ${ }^{14}$ As malignant cells likely enter the systemic circulation and establish micrometastases at a stage where the primary tumour is only a few cubic millimetres in size, factors enabling hematogeneous dissemination and metastasis should indeed be present at a very early stage. ${ }^{2}$

The majority of patients with UM will not undergo enucleation, which means that the full tumour will only be available for histopathological examination and prognostic testing in a proportion of cases. We suggest that transvitreal incisional biopsies complement FNABs in the toolbox for ophthalmologists involved in the diagnostic and prognostic work-up of UM. Consequently, BAP-1 testing can be made available for a majority of UM patients, regardless of treatment modality. Compared with FNABs, incisional biopsies have the advantage of preserved tissue architecture, a larger number of cells and a superior prognostic value. ${ }^{1213}$

Removal of tumour tissue by transvitreal biopsy has previously been proven to be safe. In reports including some of the patients presented here, no extraocular recurrences were identified among patients that had undergone transvitreal biopsy. ${ }^{16}$ In this context, it is also noteworthy that the high concordance between biopsies and enucleations reduces concern of any major influence of spatial heterogeneity in BAP-1 expression on the results of sampling only a small fraction of the tumour for analysis.

It should be noted that although loss of BAP-1 expression usually corresponds to Monosomy 3, gene expression class and mutations in the BAP-1 gene, exceptions are not rare. ${ }^{118-20}$ The expression of the protein has been shown to be a strong predictor of prognosis, independent of chromosomal status ${ }^{11}$ but not gene

\begin{tabular}{|c|c|c|c|c|}
\hline Covariate & $\begin{array}{l}\text { Regression } \\
\text { coefficient, } \\
\beta \text { (SE) }\end{array}$ & Wald statistic & $P$ value & $\begin{array}{l}\text { Hazard } \\
\text { coefficient, } \\
\text { Exp(b) }(95 \% \mathrm{Cl})\end{array}$ \\
\hline $\begin{array}{l}\text { Tumour diameter, } \\
\mathrm{mm}\end{array}$ & $0.2(0.6)$ & 7.9 & 0.005 & 1.2 (1.1 to 1.3$)$ \\
\hline $\begin{array}{l}\text { Tumour thickness, } \\
\mathrm{mm}\end{array}$ & $0.0(0.1)$ & 0.0 & 0.96 & 1.0 (0.8 to 1.3$)$ \\
\hline BAP-1 low & $2.6(0.7)$ & 12.3 & 0.0004 & 13.0 (3.1 to 54.4$)$ \\
\hline
\end{tabular}
BAP-1, BRCA1-associated protein-1. 
expression class. ${ }^{718}$ However, to the best of our knowledge, it remains to be investigated if the level of BAP-1 protein expression or BAP-1 mutation status has stronger prognostic value.

\section{Strengths and limitations}

This study is based on real patients and tumour tissues. The combination of transvitreal biopsies and subsequent enucleated eyes allows us to directly compare the concordance of BAP-1 expression in relatively small fragments of tissue with the expression in full tumours. The access to detailed clinicopathological data about tumour and patient characteristics, as well as survival data from digitalised clinical records that are accessible regardless of where in the country the patient resides, enables robust correlation to outcome where few patients are lost to follow-up. On the other hand, there are also several limitations to this study. First, the results are based on a relatively small retrospective cohort in which a proportion of patients had short follow-up. This restricts their generalisability. Second, the proportion of patients who undergo transvitreal biopsy varies between institutions. In some ocular oncology centres, our findings will only be applicable to a small group of patients with clinically indeterminate lesions. Third, the transvitreal biopsy method is mainly appropriate for tumours posterior to the equator of the eye, while anterior tumours is better accessible with transscleral techniques. Fourth, UM prognosis depends on several factors other than BAP-1 expression. For example, we did not investigate the chromosomal status and did not perform genetic tests on the tumours included here. Fifth, the method presented herein merely predicts but currently cannot improve prognosis in UM. In our clinical experience, some patients do not want to know the results of the prognostic test when faced with this reality. It is however our opinion that the more accurate factors of importance for disease-related death we identify and define, the higher the likelihood that an effective treatment can be developed.

\section{CONCLUSION}

We analysed a Swedish cohort of 59 patients with UM, diagnosed histopathologically with transvitreal incisional biopsy. The level of BAP-1 expression was classified in the biopsy material and in 21 subsequently enucleated eyes and correlated to metastasis-free survival. A large proportion of small UM had low BAP-1 expression. The expression in biopsies and enucleations correlated substantially, and patients with low BAP-1 expression in biopsies had significantly shorter metastasis-free survival. Ideally, these findings can be confirmed in future larger and prospective cohort studies. Our results also indicate the need to further study BAP-1 expression in even smaller UM, to infer the tumour size at which loss of BAP-1 starts to occur, and to correlate it with the early seeding of micrometastases.

Contributors $\mathrm{CH}$ : tissue analysis, collecting data, drafting the article, revising the article. AK: surgical procedure, collecting data, revising the article. EL: tissue collection and staining. LRC: revising the article. JW: revising the article. KB: revising the article. SS: tissue analysis, revising the article. GS: conception, tissue analysis, data analysis and interpretation, drafting the article, revising the article. All authors read and approved the final manuscript.

Funding Support for this study was provided to Gustav Stålhammar from: The Royal Swedish Academy of Sciences (reference ME2019-0036); The Swedish Society of Medicine (Cronqvists stiftelse); The Swedish Eye Foundation (Ögonfonden, reference
2020-04-27); Karolinska Institutet (reference 2019-01900); Stockholm County Council (Region Stockholm).

Competing interests None declared.

Patient consent for publication Not required.

Ethics approval The study adhered to the tenets of the Declaration of Helsinki and institutional review board approval was obtained.

Provenance and peer review Not commissioned; externally peer reviewed.

Data availability statement Deidentified raw data are available from the corresponding author on reasonable request.

Open access This is an open access article distributed in accordance with the Creative Commons Attribution Non Commercial (CC BY-NC 4.0) license, which permits others to distribute, remix, adapt, build upon this work non-commercially, and license their derivative works on different terms, provided the original work is properly cited, appropriate credit is given, any changes made indicated, and the use is non-commercial. See: http://creativecommons.org/licenses/by-nc/4.0/.

\section{ORCID iD}

Gustav Stålhammar http://orcid.org/0000-0001-9401-8911

\section{REFERENCES}

1 Singh N, Bergman L, Seregard S, et al. Clinical Ophthalmic oncology: Uveal tumors. In: Damato B, Singh AD, eds. Clinical ophthalmic oncology. Berlin, Heidelberg: Springer, 2014: 75-87.

2 Singh AD, Turell ME, Topham AK. Uveal melanoma: trends in incidence, treatment, and survival. Ophthalmology 2011;118:1881-5.

3 Kujala E, Mäkitie T, Kivelä T. Very long-term prognosis of patients with malignant uveal melanoma. Invest Ophthalmol Vis Sci 2003:44:4651-9.

4 Singh AD. Uveal melanoma: implications of tumor doubling time. Ophthalmology 2001;108:829-30.

5 Carvajal RD, Schwartz GK, Tezel T, et al. Metastatic disease from uveal melanoma: treatment options and future prospects. Br J Ophthalmol 2017;101:38-44.

6 Szalai E, Wells JR, Ward L, et al. Uveal melanoma nuclear BRCA1-associated protein-1 immunoreactivity is an indicator of metastasis. Ophthalmology 2018;125:203-9.

7 Stålhammar G, See TRO, Phillips S, et al. Digital image analysis of BAP-1 accurately predicts uveal melanoma metastasis. Trans/ Vis Sci Technol 2019;8:11.

8 Koopmans AE, Verdijk RM, Brouwer RWW, et al. Clinical significance of immunohistochemistry for detection of BAP1 mutations in uveal melanoma. Mod Pathol 2014:27:1321-30

9 Glasgow BJ, McCannel TA. Correlation of immunocytochemistry of BRCA1-associated protein-1 (BAP1) with other prognostic markers in uveal melanoma. Am J Ophthalmol 2018; 189:122-6

10 Harbour JW, Onken MD, Roberson EDO, et al. Frequent mutation of BAP1 in metastasizing uveal melanomas. Science 2010;330:1410-3.

11 Farquhar N, Thornton S, Coupland SE, et al. Patterns of BAP1 protein expression provide insights into prognostic significance and the biology of uveal melanoma. $J$ Pathol Clin Res 2018;4:26-38.

12 Robertson S, Stålhammar G, Darai-Ramqvist E, et al. Prognostic value of Ki67 analysed by cytology or histology in primary breast cancer. J Clin Pathol 2018;71:787-94.

13 Saha A, Mukhopadhyay M, Das C, et al. FNAC versus core needle biopsy: a comparative study in evaluation of palpable breast lump. J Clin Diagn Res 2016;10:EC05

14 Stålhammar G, See TRO, Phillips SS, et al. Density of PAS positive patterns in uvea melanoma: correlation with vasculogenic mimicry, gene expression class, BAP-1 expression, macrophage infiltration, and risk for metastasis. Mol Vis 2019;25:502-16.

15 Seregard S, All-Ericsson C, Hjelmqvist L, et al. Diagnostic incisional biopsies in clinically indeterminate choroidal tumours. Eye 2013:27:115-8.

16 Kvanta A, Seregard S, Kopp ED, et al. Choroidal biopsies for intraocular tumors of indeterminate origin. Am J Ophthalmol 2005:140:1002-6.

17 Cohen J. A coefficient of agreement for nominal scales. Educ Psychol Meas 1960;20:37-46.

18 TRO S, Stålhammar G, Phillips SS, et al. BAP1 immunoreactivity correlates with gene expression class in uveal melanoma. Ocul Oncol Pathol 2019:5:1-9.

19 Smit KN, van Poppelen NM, Vaarwater J, et al. Combined mutation and copy-number variation detection by targeted next-generation sequencing in uveal melanoma. Mod Pathol 2018;31:763-71.

20 Thornton S, Coupland SE, Olohan L, et al. Targeted next-generation sequencing of 117 routine clinical samples provides further insights into the molecular landscape of uveal melanoma. Cancers 2020;12:1039. 